Environment Conservation Journal 16(SE) 89-95, 2015

ISSN 0972-3099 (Print) 2278-5124 (Online)

Abstracted and Indexed

\title{
Auditing and managing energy consumption in pool of imam Khomeini University of naval forces
}

\section{Rasool Karimi}

Received:24.05.2015
Revised:28.06.2015

Accepted:30.09.2015

\begin{abstract}
In recent years, because of various reasons of auditing and calculating necessity for the rate of energy consumption and its savings have been as certain necessity. Among this, construction section has allocated more than one third of country's energy consumption to itself that its value has been determined more than 6 billion dollars annually according to world prices. Now considering less attention to energy, almost all country's buildings don't have technical regulations for preventing wasting heat or cold energy and considering that swimming pools are building with high energy consumption and energy is used there mediating various factors, this research is sought to investigate the situation of energy consumption in pool of Imam Khomeini University Of Naval Forces. The most important energy consumer factors are sidewall thermal losses with surface evaporation of pool's water and air conditioning that finally mentioned performable solutions in pool will be investigated in terms of achieving energy consumption reduction. It is tried in this study to compare performed auditing with defined standards in nineteenth discussion of national regulations and by economic evaluating and the method of calculating return on capital of each action, the priority of doing performable actions in order to reduce energy consumption is determined and compared using existing software of modeling.
\end{abstract}

Keywords: Auditing, Energy, Improvement, return on capital, Heating and cooling, Construction's thermal load

\section{Introduction}

Using energy rationally in industrial, trade and constructional environments have been paid attention by authorities as a necessity nowadays. Due to this, using energy rationally and saving it in many countries has been applied on the agenda. Auditing energy is an efficient tool for planning in this field. Stating more accurate, energy flowing balance and energy output of consumer unit can be considered as energy auditing. Energy auditing causes better perception of energy consumption methods in industry. After energy crisisin 1974, experts became interested in energy auditing to be able to manage high costs of energy consumption abuse. Auditing operations of energy in facts includes an accurate investigation about energy consumer systems that its goal is determining the kind of consuming energies, being aware of energyconsumption rate, identifying related costs and sections which have energy waste potential

Research history

M.S. Reilly et al in 1995 investigated the effects of temperature on wall thermal transmitting

\section{Author's Address}

Department Of Mechanical Engineering, Imam Khomayni University, Nowshahr, Iran.

E-mail: rasoolkarimi@gmail.com coefficient, floor, ceiling and other parts of construction. In calculating the peak of the heat absorbed from the sun, studies showed that there is more than 35 percent difference between the details of plan and constant coefficient shading of scheme. The effect of window frame, glass material and other parameters in transmitting heat and absorbing sun's heat were assessed.

Haung and Crawly investigated main variables in climate information and the way of its effectiveness on the results of energysimulation that DOE 2.IE has been used for simulation.There are many investigations about the effect of climate changes on energy consumption. Chan has promoted some of weather files based on climate changes and analyzed its effects on constructions using Energy Plus software.General shape of construction is one of outstanding features which have great effect on energy efficiency. Duarte et al have proposed a methodology for achieving accurate decision making about construction general shape considering its effects on energy efficiency. This methodology is based on flexible designing system that calculates required energy of each plan. 


\section{Methodology}

Steps taken in this research can be generally stated as follows:

1- Collecting construct's architectural plan, electrical installations, mechanical installations of pool's construction

2- Visiting pool and matching plans with constructed building

3- Applying changes of plans' differences with constructed building

4- Drawing architectural plan in 3D form using AutoCAD software

5- Defining each floor's zones

6- Converting AutoCAD file to gbxml and using this file as information in design builder software as construction's geometry definition

7- Use definition for each zone

8- Defining the structure of each zone

9- Defining openings

10- Defining lightening and its range

11- Defining heating and cooling system

12- Designing heating and cooling system

13- Model simulation

14- Analyzing outputs

\section{Energy simulation}

Technology progress in computer science has caused providing efficient tools for predicting energy consumption return of construction. Energy simulation tools model thermal, lightening, ventilation and other related parameters. Much software has been promoted in this field. Design Builder software has been used in this study that is software for modeling construction from various aspects such as construction materials, architecture, heating and cooling systems, lightening and so on. The other capability of this software is modeling mechanical and natural ventilation, calculating the rate of energy receiving waste and so on. The results of modeling can be extracted for whole year, various months daily and hourly.

Considering that this software is known in Iran recently and has not been used for poll location (Mazandaran Province, Nowshahr) up to now, therefor the goal of using that is discovering new and updated software practical capabilities for simulating pool's construction.

\section{Case study}

The pool of Imam Khomeini Naval Forces University with infrastructure of 3100 square meters located in Mazandaran Province, Nowshahr has two floors and don't have basement. Considering the average annual rainfall of $780 \mathrm{~mm}$ in Mazandaran province and the average annual temperature of 9 to 17 degrees Celsius based on Domarten index,Nowshahr town is considered as Caspian moderate climate. On average per year Nowshahr town requires 3000 degree / day heating and approximately 200 degree / day cooling.Pool's construction is for appendix table 5 of construction's national regulations, nineteenth discussion of group 4 (bulidings without saving energy) that it shows the necessity of saving energy and investigating this complex.

\section{Results and discussion}

Their results are analyzed and investigated in this section. After modeling current building of pool using Design Builder software, improvement was done due to reducing fuel consumption. Improved parameters and their abbreviations are shown in table 1.

The original model(As-is Case) AIC

Change orientationofbuilding

(Changedorientation)

OT

Addtheshadingon the windows

(Addedshadingonwindows)

WS

Windowsimproving

(Windowsofthebuildingimproved)

WI

Walls, floorandroofimproving

(Improvedwalls, floorandroof)

ENV

Inside airinfiltrationimproving

(airtight)

(Theimprovedinfiltrationlevels)

INF

Lightingimproving

(Lightingimproved)

LGT

Air Conditioning System improving

(Cooling-Heating)(ImprovedHVAC)

HVAC

Table 1- List of naming amendments to the original model 


\section{Change orientation of building}

The direction of building was changed to east-west one (The angle of zero degree in software). Considering the existence of numerous windows in south direction, it is more likely to have more sunlight from south direction in winter. Although this change has little effect on building's energy consumption, but they need to be taken in primary levels of designing.

\section{Addingtheshading on the windows}

Adding a steel shade with angle of 90 degree and height of 1.5 meter to all outside windows, causes reducing entry excess heat of sun in warm seasons into building and as result it causes required cooling's energy reduction.

\section{Improving windows}

The last performed revision on windows, is replacing aluminum frames with U.P.V.C frame. Considering that windows frames are considered as thermal bridge, using materials with low thermal transmitting coefficient causes reducing energy waste.Thermal features of modified windows (glass and frame) are shown in table 2.

\section{Walls, floor and roof improving}

Considering main building energy simulation outputs, noticeable value of energy waste is allocated to outside walls and some of it to roof and floors. In this section outside walls are insulated using Expandable polystyrene (EPS) to a thickness of $5 \mathrm{~cm}$. moreover autoclave foam concrete has been used in internal layer (toward building inside). In building's roof also Expandable polystyrene (EPS)to a thickness of $7.5 \mathrm{~cm}$ has been utilized. Main and improved wall thermal features are according to table 3 .

\begin{tabular}{|c|c|c|c|c|}
\hline $\begin{array}{c}\text { SHGC } \\
\text { (Efficiencysolarthermalcoefficientofglass) }\end{array}$ & 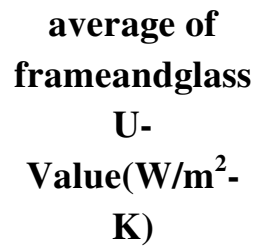 & $\begin{array}{c}\text { Frame } \\
\text { U- } \\
\text { Value }\left(\mathbf{W} / \mathbf{m}^{2} \text { - }\right. \\
\mathbf{K})\end{array}$ & $\begin{array}{c}\text { Glass } \\
\text { U- } \\
\text { Value(W/m²- } \\
\text { K) }\end{array}$ & \\
\hline 0.703 & 4.273 & 5.881 & 2.665 & AIC \\
\hline 0.643 & 2.4845 & 3.476 & 1.493 & WI \\
\hline
\end{tabular}

Table 2: main and improved windows' thermal transmitting coefficient

\section{Inside airinfiltrationimproving (airtight)}

Infiltration or the rate of air penetration inside is because of uncontrolled air Entry through cracks, holes, etc. the rate of infiltration is stated with the rate of air changes in hour.

\section{Lightening improving (LGT)}

After reducing the noticeable value of consuming gas using insulating building, lightening will be important. With changing the kind of consuming lamps from fluorescent to the best one offered by Design Builder software with higher radiation coefficient, ideal results have been accomplished in the field of energy consumption reduction.

\section{Cooling-heating system improving (HVAC)}

The last performed revision is related to coolingheating system. Direct use of these systems from energy, has made improving and true selection of cooling-heating installation more important. In order to this, a system of VAV systems is defined. In improved system, mechanical air conditioning is used instead of natural one and return coefficient of cooling from 2 to 3.5 and heating from 0.7 to 1 has been changed. The important point here refers to that although with air tightening the building, energy consumption was reduced but for changing the air and providing fresh air required by residents, using a mechanical air conditioning, carbon dioxide and other harmful gases out of furniture and constructional elements will go out from home environment and instead of that fresh air will enter the building.In table 4, related results to reducing energy consumption are shown in various fields which are the result of accomplishing revisions and improvement. 
Karimi

\begin{tabular}{cccc}
\hline roof top & Interiorfloor & Exterior walls \\
U-Value & U-Value & 1.557 & \\
\hline $\mathbf{0 . 2 0 6}$ & 2.065 & 0.326 & AIC \\
$\mathbf{0 . 1 6 0}$ & 0.420 & ENV \\
\hline
\end{tabular}

Table 3:Main and improved wall thermal features coefficient

\begin{tabular}{cccccc}
\hline Optimizationtype & \multicolumn{5}{c}{ Reduction percent } \\
\hline & $\begin{array}{c}\text { electricity } \\
\text { consumption }\end{array}$ & $\begin{array}{c}\text { Gas } \\
\text { consumption }\end{array}$ & $\begin{array}{c}\text { Cooling } \\
\text { energy }\end{array}$ & $\begin{array}{c}\text { Heating } \\
\text { energy }\end{array}$ & $\begin{array}{c}\text { CO2 } \\
\text { production }\end{array}$ \\
OT & 0.87 & 1.3 & 1.6 & 7.6 & - \\
WS & 0.87 & 1.3 & 2.85 & 10.11 & - \\
WI & 0.87 & 1.3 & 2.42 & 11.54 & - \\
ENV & 6.1 & 11.69 & - & 83.85 & 6.01 \\
INF & 6.1 & 12.99 & - & 92.45 & 14.12 \\
LGT & $27.27 \%$ reduction in theneeded energy forlightingand7.8\% reduction of total \\
HVAC & 15.18 & 13.73 & electricityconsumption \\
\hline
\end{tabular}

Table 4- related results to energy consumption reduction because of various improvements

Figures 1 to 5 respectively show the rate of gas, electricity, fuel, energy for cooling and heating consumption in different modes of improvement.

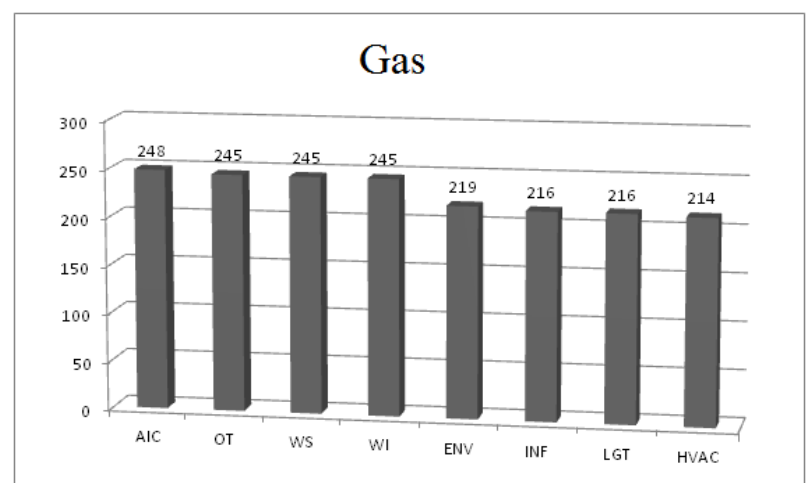

Figure 1- the diagram of comparing gas consumption in improving different modes $\left(\mathrm{KWh} / \mathrm{m}^{2} / \mathrm{yr}\right)$

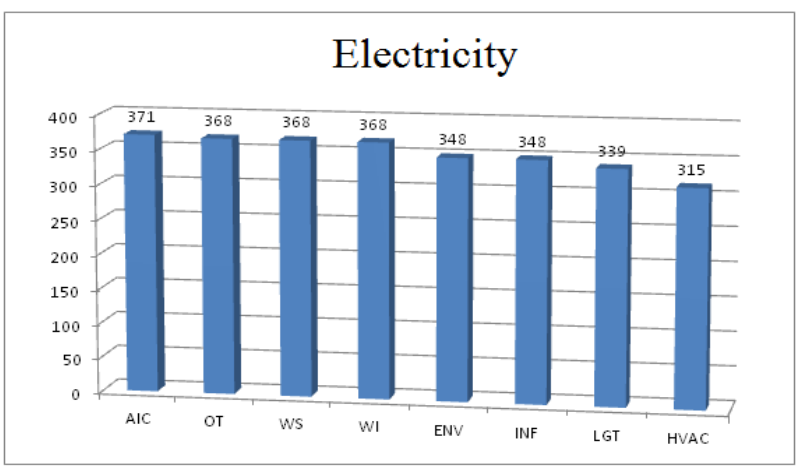

Figure 2- the diagram of comparing electricity consumption in improving different modes $\left(\mathrm{KWh} / \mathrm{m}^{2} / \mathrm{yr}\right)$

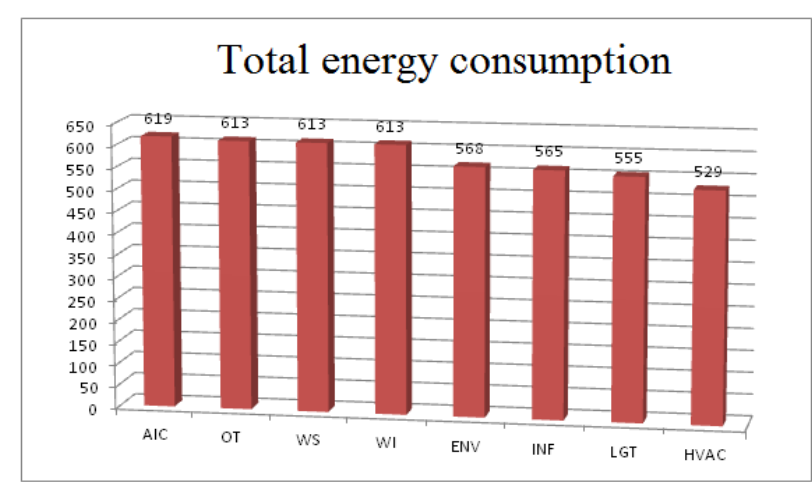

Figure 3- the diagram of comparing total fuel consumption (gas and electricity) inimproving different modes $\left(\mathrm{KWh} / \mathrm{m}^{2} / \mathrm{yr}\right)$

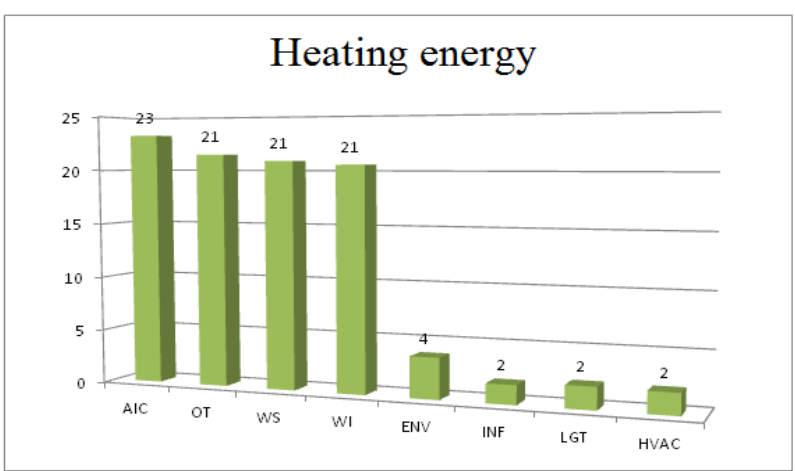

Figure 4- the diagram of heating energy consumption in improving different modes $\left(\mathrm{KWh} / \mathrm{m}^{2} / \mathrm{yr}\right)$ 


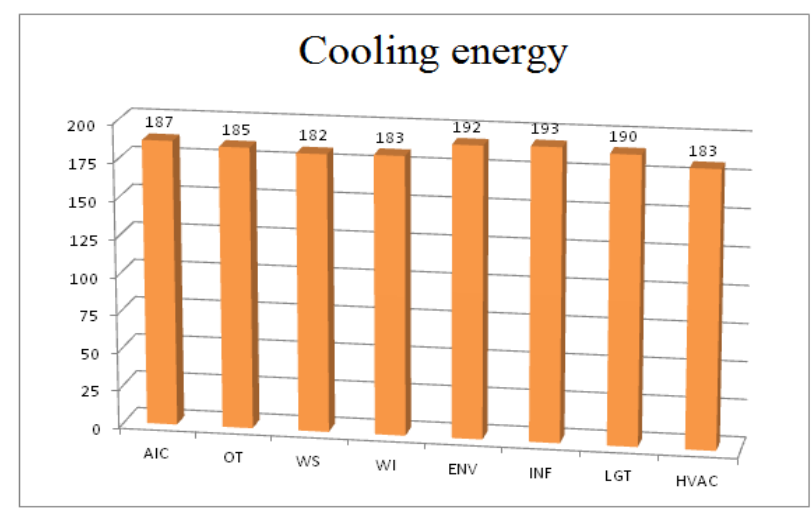

Figure 5- the diagram of cooling energy consumption in improving different modes $\left(\mathrm{KWh} / \mathrm{m}^{2} / \mathrm{yr}\right)$

\section{Conclusion}

1- Applying architectural regulations that cause saving energy, is the first step in achieving this goal in construction section. Because of this, in designing section, efficient energy architectural design tips should be taken into account. It is noticeable that applying these regulations won't cost a lot.

\section{References}

California Air Resources Board 2009a. AB 32 cost of implementation fee regulation. Sacramento, CA.

California Air Resources Board 2009b. Proposed AB 32 cost of implementation fee regulation and proposed amendment to the mandatory reporting of greenhouse gas emissions regulation. Sacramento, CA.

Carbon Reduction Commitment 2010.Carbon reduction commitment energy efficiency scheme. United Kingdom. 2013.

Environmental Protection Agency 2011.Inventory of US greenhouse gas emissions and sinks: 1990-2009. United States.

Environmental Protection Agency 2012a.Causes of Climate Change.From, Accessed on 11January 2013, from http://epa.gov/climatechange/science/causes.html\#greenho useeffect.

Environmental Protection Agency 2012b.Glossary of climate change terms.Climate change.From, Accessed on 11 January, 2013, from http://www.epa.gov/climatechange/.

Environmental Protection Agency 2012c.United States greenhouse gas inventory report.Climate Change. United States. 2012.
2- Using insulation material in outside construction of building such as window and wall is one of the important reducing factors of heating energy consumption. Considering that using insulation in Iran isn't that much common, one of the important actions due to this is proposing cash contributions of government in order to buy and use them.

3- By preventing leakage of air infiltration inside, energy waste will reduce. This case should be noticed by constructors in construction level.

4- The most important section in building that must be paid attention in order to reduce energy assumption is choosing heating-cooling system's kind.

5- Through improving each one of above factors, changes can be seen in carbon dioxide emissions. Therefor using mentioned cases not only causes energy consumption reduction but also causes reducing greenhouse gases. Of course it should be noticed that in vaster scale, more significant reduction in carbon dioxide can be seen.

European Union Commission 2003a. Directive 2003/87/EC of the European Parliament and of the Council of 13 October 2003 establishing a scheme for greenhouse gas emission allowance trading within the Community and amending Council Directive 96/61/EC. Oficial Journal of the European Union.Brussels, Belgium, Oficial Journal of the European Union.275.

European Union Commission 2003b.Directive 2003/96/EC restructuring the Community framework for the taxation of energy products and electricity.Brussels, Belgium Oficial Journal of the European Union.

European Union Commission 2009. EU action against climate change: The EU Emissions Trading Scheme. E. Communities. Brussels, Belgium.

European Union Commission 2011a. Europe 2020 Targets: climate change and energy. Brussels, Belgium. 2012.

European Union Commission 2011b.Proposal for a Council Directive amending Directive 2003/96/EC restructuring the Community framework for the taxation of energy products and electricity. Brussels, Belgium. 163.

European Union Commission 2012. Making it happen: the European semester. Annual Europe 2020 policy coordination exercise. Brussels, Belgium. 
Goldblatt, M. 2010.Comparison of emissions trading and carbon taxation in South Africa.Climate Policy.10(5): 511526.

Government of Alberta 2010.Regulating greenhouse gas emissions, Environment and Sustainable Resource Development of Alberta. 2012.

Government of Alberta 2011.Environment annual report 2010 - 2011.E. o. Alberta. Alberta.

Government of Australia 2010. Greenhouse gas reduction scheme (GGAS).

Government of Australia 2011a. Clean Energy Bill: Act No. 131 of 2011 as made an Act to encourage the use of clean energy, and for other purposes. D. o. C. C. E. Efficiency. Australia.

Government of Australia 2011b. Fact Sheet 500 Biggest Polluting Companies. Australia.

Government of Australia 2012.Quarterly update national greenhouse gas inventory.Quater 2012. Australia. 2012.

Government of Canada 2011.National Inventory Report. Greenhouse Gas Sources and Sinks in Canada. 1990-2010. Executive Summary. Gatineau, Canada.

Government of Japan 2012a. National GHGs inventory report of Japan. Japan. 2012.

Government of Japan 2012b.Policy tax. Japan.

Government of New Zealand 2009.Summary of the proposed changes to the NZ ETS.M. f. t. Environment. New Zealand. 11.

Government of New Zealand 2012a.New Zealand's greenhouse gas inventory 1990-2010, Ministry for the Environment.2012.

Government of New Zealand 2012b.New Zealand's greenhouse gas inventory 1990-2010, Ministry for the Environment. 2012.

Government of Switzerland 2008.The national emissions trading registry.

Government of Tokyo 2011.Tokyo cap-and-trade program Japan.2012.

Government of United States 2008. Fact sheet: proposed Bay Area Air Quality Management District greenhouse gas fee schedule. United States.

Government of United States 2009. Climate action plan excise tax. C. o. Boulder. Colorado, United States. Ordinance No. 7657

Government of United States 2010. Act to establish a reliable funding source for greenhouse gas reduction programs in the form ofan excise tax on major emitters of carbon dioxide. Meryland, United States.

Han, G., Olsson, M., Hallding, K.andLuderer, G. 2012.China Carbon Emissions Report. Stockholm, Sweden. 2012.

Hedberg, D., Kullander, S.and Frank, H. 2010. The world needs a new energy paradigm. AMBIO.39(1): 1-10.

Ishihara, A. 2008.Development of Energy Conservation Policy, Law, and Management Concept in Japan. T. E. C. Centre. Japan.

Joint Research Center 2012. Emissions database for global atmospheric research (EDGAR). Version 4.2, Netherlands Environmental Assessment Agency. 2012.

Joint Research Centre 2012.Emission database for global atmospheric research PBL Netherlands Environmental Assessment Agency.

Lincoln, S. F. 2012. Options for change in the Australian energy profile. $A M B I O .41(8): 841-850$.

National Greenhouse and Energy Reporting Act 2007.National Greenhouse and Energy Reporting Act, Austraian Government.

Perdan, S.andAzapagic, A. 2011. Carbon trading: Current schemes and future developments. Energy Policy.39(10): 6040-6054.

Pew center on global climate change 2007. Climate change mitigation measures in the people's Republic of China. Arlington, United States. 2012.

Regional greenhouse gas initiative 2012. Annual report on the market for RGGI CO2 allowances: 2011. United States. 2012 .

Steckel, J. C., Jakob, M., Marschinski, R.andLuderer, G. 2011.From carbonization to decarbonization?Past trends and future scenarios for China's $\mathrm{CO} 2$ emissions.Energy Policy. 39(6): 3443-3455.

Sumner, J., Bird, L.andDobos, H. 2011. Carbon taxes: a review of experience and policy design considerations. Climate Policy.11(2): 922-943.

United Nations Framework Convention on Climate Change 1998.Kyoto Protocol. Japan.

United Nations Framework Convention on Climate Change 2008. Kyoto protocol reference manual on accounting of emissions and assigned amounts. Germany.

United Nations Framework Convention on Climate Change 2010. Appendix I - Quantified economy-wide emissions targets for 2020. 2012. 


\section{Auditing and managing energy}

United Nations Framework Convention on Climate Change 2012.Greenhouse Gas Inventory Data.2012.

Wrake, M., Burtraw, D., Lofgren, A.and Zetterberg, L. 2012. What have we learnt from the European Union's emissions trading system? AMBIO. 41(1): 12-22.
Zetterberg, L., Wrake, M., Sterner, T., Fischer, C.andBurtraw, D. 2012.Short-run allocation of emissions allowances and long-term goals for climate policy.AMBIO. 41(1): 23-32. 